\title{
Coronavírus em tempos de crise humanitária
}

\section{Francisco Jameli Oliveira Reinaldo ${ }^{1}$ Victor Sérgio Freire Araújo²}

\footnotetext{
1 Mestre em Filosofia pela Universidade Estadual do Ceará - UECE. Graduado em Filosofia pela Universidade Estadual Vale do Acaraú. Graduando em Psicologia pela Universidade Federal do Ceará. Membro do Grupo de Estudos em Política, Educação e Ética - GEPEDE/UEVA/CNPQ. E-mail: dulitle@hotmail.com Orcid: http://orcid.org/0000-0003-2696-0328

2 Bacharel em Ciências Econômicas pela Universidade Pitágoras Unopar e licenciando em Ciências Sociais pela Universidade Estadual Vale do Acaraú.

E-mail: victorsergiofa@gmail.com Orcid: http://orcid.org/0000-0001-5480-4045
}

RESUMO: O artigo que se segue, baseado na metodologia exegética das obras de pensadores das ciências humanas, formula reflexões acerca de um evento cujo distanciamento e imparcialidade são impossíveis. O caráter ensaístico da escrita é, neste sentido, exigência do próprio evento em análise. Escrevemos com o triplo objetivo de (a) refletir para compreender, (b) para enfrentar e resistir ao problema, (c) não para fornecer respostas, mas para enfatizar a relação entre o problema da pandemia, em si mesmo grave, mas que sinaliza um a crise humanitária inserida no âmago do capitalismo. Dessa forma, o presente artigo aborda a pandemia do coronavírus de maneira que possibilite contribuir para uma melhor compreensão do fenômeno que estamos experienciando. Para isso, de início, analisa-se a atual pandemia em suas relações com a modernidade e seu caráter globalizante. Em seguida, destaca-se as consequências das políticas neoliberais que tornaram o cenário pandêmico em uma crise dentro da crise. Para tanto, desembocando no dilema que o neoliberalismo impõe à humanidade, o lucro ou as pessoas, expõem-se nitidamente as fissuras do capitalismo. Por fim, analisa-se a atuação da necropolítica e da vigilância na pandemia. Os resultados da pesquisa indicam que a gravidade dos impactos da pandemia resulta (a) da tensão moderna entre segurança e perigo, isto é, do desenvolvimento das tecnologias e do potencial destrutivo de nossa técnica, (b) do desenvolvimento da lógica neoliberal capitalista, que, em conclusão, elege vidas como supérfluas e enuncia a crise global do capitalismo.

Palavras-chave: Pandemia. Crise. Coronavírus.

ABSTRACT: The following article, based on the exegetical methodology of the works of humanities thinkers formulates reflections on an event whose detachment and impartiality are impossible. The essayistic character of writing is, in this sense, a requirement of the event itself under analysis. We write with the triple objective of (a) to reflect to understand, (b) to confront and resist the problem, (c) not to provide answers, but to emphasize the relationship between the pandemic problem, serious in itself, but that signals a humanitarian crisis inserted the heart of capitalism. Thus, this article addresses the coronavirus pandemic in a way that makes it possible to contribute to a better understanding of the phenomenon we are experiencing. To this end, the current pandemic is firstly analyzed in its relations with modernity and its global character. Then, the consequences of neoliberal policies that turned the pandemic scenario into a crisis within the crisis are highlighted. To do so, ending in the dilemma that neoliberalism imposes on humanity, profit or people, the fissures of capitalism are clearly exposed. Finally, the role of necropolitics and surveillance in the pandemic is analyzed. The search results indicate that the severity of the pandemic impacts results from (a) the tension between safety and danger, namely, the development of technologies and the destructive potential of our technic, (b) of the development of neoliberal capitalistic logic that, in conclusion, elects lives as superfluous and enunciate the global crisis of capitalism. 


\section{Keywords: Pandemic. Crisis.Coronavirus.}

\section{Introdução}

Gostaríamos de começar com uma justificativa: não é possível formular uma reflexão que se pretenda minimamente consistente sem levar em consideração o caráter fugidio do assunto em questão. Os verdadeiros impactos dessa pandemia somente virão à luz quando ela seguramente for um fenômeno do passado.

A complexidade do atual contexto de pandemia torna possíveis diversas análises. Tendo em vista a complexidade e a dificuldade de escrever sobre um fenômeno e vivê-lo, simultaneamente, concordamos com Santos (2020, p. 13), quando este afirma, sobre a pandemia, que "qualquer tentativa de aprisioná-la analiticamente está condenada ao fracasso, dado que a realidade vai sempre adiante do que pensamos ou sentimos sobre ela. Teorizar ou escrever sobre ela é pôr as nossas categorias e a nossa linguagem à beira do abismo".

Nesse caso, o caráter ensaístico, experimental, da escrita é exigência do próprio evento em consideração. Pode ser que parte das reflexões que tenhamos aqui sejam completamente revistas instantes depois da publicação do presente texto. É necessária a complacência do leitor para com os autores, complacência, ademais, que encontra contrapartida na modéstia das reflexões aqui elaboradas.

Como um historiador que só alça a compreensão do evento histórico quando seguramente observa à distância, nas palavras de Hegel (1997, p. 39), "quando as sombras da noite começaram a cair é que levanta voo o pássaro de Minerva”, quando camadas de eventos já se acomodaram no tempo, também nós assumimos o risco de, no calor das discussões, valorar demais a tragédia, se for o caso, ou, de outra maneira, minorar a catástrofe confiando no potencial transformador da ciência.

É possível verificar através da ferramenta Google Trends que os termos "coronavírus", "pandemia" e "Covid-19" tiveram uma quantidade de buscas no Google bastante inexpressivas no Brasil, até chegarmos ao mês de março de 2020, quando houve um aumento exponencial nas buscas por esses termos. Pandemia, coronavírus, Covid-19, são palavras que agora permeiam nosso cotidiano, concomitante aos efeitos delas advindos, o isolamento social, caos na saúde pública, recessão econômica, para nomear os principais.

Badiou (2020, p. 37) afirma que "uma epidemia se torna complexa pelo fato de ser sempre um ponto de articulação entre as determinações naturais e sociais". Diante disso, o que podemos dizer, de início, é que não sabemos o que acontecerá; escrevemos para dispersar esta névoa que sombreia nossos tempos de fake news, de crises política e econômica, em que o bom-senso é constantemente desafiado pelo pseudo problema da escolha entre vidas e economia, por teorias da conspiração de todas as ordens e discursos de ódio por todos os lados. Também nós escrevemos para tentar compreender.

Se sob formulações generalizantes ocultamos o caráter ensaísticos da escrita é porque sob parâmetros históricos anteriores, de crises semelhantes a que agora enfrentamos, tentamos minimizar a novidade do evento em análise. Não. A pandemia, nela mesma, não é novidade, é claro. Mas a atmosfera em que ela ocorre não encontra precedentes históricos.

O presente ensaio apresenta, em linhas gerais, a seguinte reflexão: refletiremos sobre o que podemos vislumbrar como novidade desafiadora que se insurge com esta pandemia considerando que, uma vez que a ocorrência do evento, paralela à nossa escrita, impede uma visão panorâmica, sóbria, do evento, procuramos refletir sobre a pandemia à luz de fenômenos que a precederam e que a contextualizam.

Santos (2020, p. 23) afirma que "a pandemia do coronavírus é uma manifestação entre muitas do 
modelo de sociedade que se começou a impor globalmente a partir do século XVII e que está hoje a chegar à sua etapa final", ou seja, a pandemia é uma manifestação da própria modernidade. Contextualizando historicamente o fatono que, segundo Guiddens (1991), podemos classificar como "consequências da modernidade", assim pensamos, poderemos compreender melhor a crise que agora enfrentamos.

\section{Pandemia e modernidade}

Vivemos um período histórico que filósofos como Lyotard e Vattimo caracterizam como pós-modernidade, com o fim das grandes narrativas - Lyotard - e um pensamento fraco - Vattimo -, caracterizado pelo declínio dos mega-discursos com pretensão de abarcar a totalidade do real (GIDDENS, 1991). Outros, como Giddens, testemunham em favor de uma modernidade ainda não superada e que só agora apresenta suas consequências mais radicais e universalizadas (GIDDENS, 1991, p. 13).

Giddens (1991, p. 17) e Elias (1997), caracterizam nosso período como uma tensão constante entre segurança e perigo. Nas palavras de Elias, uma simples descoberta, como a descoberta do fogo, dentre outras, é suficiente para revelar a dupla face da modernidade.

Tal como a descoberta do fogo permitiu que o alimento fosse cozido, assim como a destruição de cabanas e casas pelas chamas; tal como a invenção da metalurgia acarretou grande progresso na agricultura e na guerra; tal como a energia atômica pôde ter um uso pacífico como fonte energética e ser uma arma terrível, também as invenções sociais são bifrontes. (ELIAS, 1997, p. 162).

De igual maneira, Giddens assume que o que ele caracteriza como modernidade passa hoje por consequências cada vez mais globalizantes. Compreender as consequências da modernidade é encarar com sobriedade o caráter ambíguo do evento histórico em análise. Nas palavras do autor:

O desenvolvimento das instituições sociais modernas e sua difusão em escala mundial criaram oportunidades bem maiores para os seres humanos gozarem de uma existência segura e gratificante que qualquer tipo de sistema pré-moderno. Mas a modernidade tem também um lado sombrio, que se tornou muito aparente no século atual. (GIDDENS, 1991, p. 17).

Ainda no século anterior, Giddens já esclarecia a ambivalência da modernidade. Na civilização das novas tecnologias deste século os impactos globalizantes da modernidade se fazem notar quase que de maneira imediata. Harvey (2020, p. 16) ao analisar epidemias anteriores e a atual, destaca uma das desvantagens da crescente globalização: “ser impossível deter uma rápida difusão internacional de novas doenças. Vivemos em um mundo altamente conectado, onde quase todos viajam. As redes humanas de difusão potencial são vastas e abertas".

É surpreendente que em menos de seis meses o que era o problema de uma pequena província chinesa transformou-se numa pandemia global, paralisando grandes instituições financeiras, desafiando nações desenvolvidas e em desenvolvimento, mobilizando esforços, diga-se de passagem, até agora pouco eficazes, para combatê-la.

Neste sentido, parece-nos que é frutífero encarar nosso período à luz da tensão constante entre segurança e perigo, como fizeram Elias (1997) e Giddens (1991). É desse ponto que partimos.

Se por um lado os ganhos tecnológicos da economia capitalista expandem-se rapidamente, os prejuízos da lógica globalizante do capital também infestam rapidamente o globo, desafiando a lógica instrumental da própria economia capitalista. E não só isso. Até os limites geográficos das nações, numa economia de 
mercado globalizante, com desenvolvimento de transportes aéreos e mídias sociais acessíveis a praticamente toda a população, são desafiados. Essas interconexões dão-nos a sensação de que não existem fronteiras.

Consequência natural dessa ausência de fronteiras - há muito até mesmo o céu deixou de ser o limite de nossas ambições colonizadoras -, segundo Mike Davis, a pandemia revela que "a globalização capitalista parece agora biologicamente insustentável na ausência de uma verdadeira infraestrutura de saúde pública internacional" (DAVIS, 2020, p. 12).

Esta é, ademais, a primeira pandemia que enfrentamos on-line. Recebemos, frequentemente, uma enxurrada de informações, falsas, muitas delas, e mesmo as verdadeiras, é difícil filtrar quais sejam relevantes. Ansiedade e medo, reais ou ilusórios, factuais ou conspiratórios, também contribuem para condições de adoecimento.

As estatísticas, a despeito das subnotificações, são capazes de contabilizar os infectados, mortos e recuperados. Nossa preocupação imediata é com a diminuição da curva de contágio. Morin (2020) destaca, em entrevista, que a atual pandemia nos forçou a desacelerar e que o confinamento faz com que valorizemos mais a cultura e outros saberes que estão fora da lógica instrumental do mercado, ou seja, que não geram lucros, ou que não têm o lucro como fim imediato. Apesar disso, os efeitos psicológicos de mudança de hábitos só serão compreendidos com clareza depois do fim da pandemia.

\section{A crise dentro da crise}

É um fato quase unânime que nossa sociedade não estava preparada para este problema da pandemia. Alguns motivos para isto são bem destacados por Mike Davis (2020) em seu artigo A crise do coronavírus é um monstro alimentado pelo capitalismo. Ele analisa as causas que levaram o sistema de saúde dos EUA a uma situação de despreparo para enfrentar a crise do coronavírus.

Davis (2020) detalha como reduziu-se a capacidade do atendimento para epidemias e emergências médicas. Tal redução, no setor público ocorre, sobretudo, devido à austeridade fiscal, enquanto que, no setor privado, a medicina de emergência não é considerada lucrativa. Portanto, ambos os setores, público e privado, sofreram na lógica do neoliberalismo, até chegarmos nesta situação. Em última instância, o lucro como finalidade soberana do nosso sistema econômico deixou, principalmente, os pobres à própria sorte, nesta crise.

Estamos diante de uma situação na qual o Estado tornou-se peça-chave para combater a pandemia. Porém, em grande parte do mundo, ele não está preparado para enfrentá-la. O quadro torna-se compreensível quando tomamos consciência, como estabelece Santos (2020), de que não estamos vivendo uma contraposição entre crise e normalidade: estamos em uma crise dentro da crise global do capitalismo.

Adentrando a discussão acerca do modelo neoliberal, Santos (2020) expõe, de maneira breve, o surgimento histórico dessa forma dominante do sistema capitalista atual:

[...] nos últimos quarenta anos, sobretudo depois da queda do Muro de Berlim. Impôs-se a versão mais antissocial do capitalismo: o neoliberalismo crescentemente dominado pelo capital financeiro global. Esta versão do capitalismo sujeitou todas as áreas sociais - sobretudo saúde, educação e segurança social- ao modelo de negócio do capital, ou seja, a áreas de investimento privado que devem ser geridas de modo a gerar o máximo lucro para os investidores. Este modelo põe de lado qualquer lógica de serviço público, e com isso ignora os princípios de cidadania e os direitos humanos. (SANTOS, 2020, p. 24).

O neoliberalismo como versão atual e dominante do capitalismo avança sobre o setor público, 
sujeitando-o à perversa lógica do lucro, que "assenta [-se] cada vez mais no capital fictício e numa vasta expansão na oferta de dinheiro e na criação de dívida”. (HARVEY, 2020 p. 14).

Zizek (2020, p. 46-47) aponta que neste atual contexto de pandemia houve o retorno triunfante do animismo capitalista, que significa "tratar fenômenos sociais, como mercados ou capital financeiro, como se fossem organismos vivos", em suas palavras. E acrescenta: "se você ler a grande mídia, a impressão que você tem é que são os 'mercados ficando nervosos' que deveriam nos preocupar, e não os milhares de pessoas que morreram e os milhares que ainda não morreram”.

Na mesma direção do animismo capitalista que Zizek (2020) observa, Santos (2020), ao discutir o quanto a política afastou-se das funções as quais deveria exercer, a coloca como mediadora das "necessidades e aspirações dos mercados, esse megacidadão informe e monstruoso que nunca ninguém viu nem tocou ou cheirou, um cidadão estranho que só tem direitos e nenhum dever” (SANTOS, 2020, p. 10).

Dessa forma, em um contexto de pandemia global, pode-se constatar nitidamente uma preocupação com esse megacidadão chamado mercado financeiro, em detrimento de segmentos sociais mais vulneráveis. Prova disso é tal ação do Presidente dos EUA, Donald Trump:

O Presidente Trump fez uma imitação do Rei Canuto diante de uma potencial maré crescente de doenças e mortes. Algumas das respostas são estranhas. Fazer com que a Reserva Federal baixasse as taxas de juros diante de um vírus parecia estranho, mesmo quando se reconhecia que o movimento se destinava a aliviar os impactos do mercado e não conter o progresso do vírus. (HARVEY, 2020, p. 17)

A condução política que o neoliberalismo impõe faz com que pensemos no questionamento que dá nome a um livro de Noam Chomsky: o lucro ou as pessoas? Quais escolhas estamos tomando?

\section{O lucro ou as pessoas?}

Recentemente, alguns intelectuais que realizaram reflexões e análises sobre a atual pandemia têm demonstrado como a lógica do lucro tem dominado a indústria farmacêutica. Tal exemplo, dado o contexto, ilustra perfeitamente a condição que a humanidade está submersa.

Chomsky (2020), Davis (2020) e Harvey (2020) expõem que a indústria farmacêutica está mais interessada em produzir cremes corporais, tranquilizantes viciantes, remédios para tratar a impotência sexual do que em produzir vacinas e pesquisar novos antibióticos e antivirais. Apesar de que, há décadas, exista a possibilidade da criação de uma vacina universal contra a gripe, esta não é considerada lucrativa o suficiente para ser colocada como prioridade, uma vez que, quanto mais as pessoas adoecem, mais a indústria farmacêutica lucra.

No dilema entre o lucro ou as pessoas, a balança pende em favordo lado lucro. O autor traz também o exemplo dos asilos, epicentros da pandemia na Europa. Davis (2020) coloca tal setor como o locus onde são mais visíveis as contradições mortais dos cuidados de saúde privados numa época de peste: "muitos destes asilos acham mais barato pagar multas por violações sanitárias do que contratar funcionários adicionais e dar-lhes formação adequada”. (DAVIS, 2020, p. 10).

Nessa situação ilustrada por Mike Davis, a saúde dos idosos se submete aos mais elevados riscos. O coronavírus representa para eles um perigo mortal, não apenas porque pertencem ao chamado grupo de risco, mas pelo descaso inerente à opção pelo lucro.

Sobre a crescente dominação da lógica do lucro conduzindo a uma forte crise humanitária, Mbembe (2017) afirma que estamos nos aproximando do fim da era do humanismo. Diante da impossibilidade cada 
vez maior da existência simultânea de capitalismo e democracia, a política será uma guerra mal sublimada, uma guerra que não dissolve o social, mas que tem como alvo todo o tipo de minoria e de pessoas a margem na sociedade. O horizonte que se desenha é de que o mercado estará em sua máxima supremacia e ditando as normas para as outras esferas da vida social.

A lógica do lucro nesse período de pandemia vem cada vez mais dando nitidez à desigualdade social mundial. O nosso sistema econômico, em períodos críticos como o nosso, atesta que os ganhos do capitalismo são reais apenas para uma pequena parcela da humanidade. Sob este cenário, é oportuno refletir sobre a divisão de classes na pandemia.

\section{Divisão de classes na pandemia}

O isolamento social não será igual para todos. A desigualdade na quarentena se origina, sobretudo, nas desigualdades sociais já existentes. Enquanto uns não têm nem casa para se manterem em isolamento social e outros trabalham na rua pra garantir a própria sobrevivência e a da família, os ricos, estes sim irão se confinar em suas capsulas extradimensionais esperando tudo voltar à normalidade, ou seja, o status quo ante, que para grande parte da população mundial representa um verdadeiro pesadelo.

Santos (2020, p. 15) afirma que "qualquer quarentena é sempre discriminatória, mais difícil para uns grupos sociais do que para outros e impossível para um vasto grupo de cuidadores, cuja missão é tornar possível a quarentena ao conjunto da população". De fato, haverá muitas pessoas que estarão na linha de frente nessa pandemia devido às suas atribuições profissionais.

No entanto, o mais nítido contraste está no que representará a quarentena para as camadas mais favorecidas e para as camadas mais vulneráveis socialmente. No Brasil já é possível notar que, não apenas os idosos estão realmente incluídos no grupo de risco, mas também os pobres. O mesmo fenômeno se pode notar nos Estados Unidos:

O surto expôs instantaneamente a divisão de classes na saúde americana. Aqueles com bons planos de saúde que também podem trabalhar ou ensinar de casa estão confortavelmente isolados, desde que sigam salvaguardas prudentes. Os funcionários públicos e outros grupos de trabalhadores sindicalizados com cobertura decente terão de fazer escolhas difíceis entre renda e proteção. Enquanto isso, milhões de trabalhadores com baixos salários, trabalhadores rurais, desempregados e sem teto estão sendo jogados aos lobos. (DAVIS, 2020, p. 9).

Esse cenário não deixa qualquer margem de dúvida sobre a dinâmica do funcionamento do conflito de classes. Enquanto as políticas neoliberais trataram de sucatear o sistema de saúde público em favorecimento do lucro de determinadas corporações, a elite econômica, hoje, desfruta de um isolamento social confortável, enquanto os pobres, nos termos de Mike Davis (2020), estão sendo jogado aos lobos.

O neoliberalismo, que impunha uma política de recrudescimento do Estado, de menos investimento em saúde, se mostra ineficiente diante de problemas dessa natureza. Como esclarece Davis, a pandemia solicita uma infraestrutura de saúde pública internacional, não porque os efeitos se farão sentir igualmente em todos os países do globo e em todas as classes - não estamos no mesmo barco! ${ }^{1}$-, mas porque somos

\footnotetext{
1 Até onde se sabe, além de uma faixa-etária específica mais vulnerável, os idosos, há condições específicas que favorecem em muito a propagação do vírus. Se for verdade que, uma vez que ainda não encontramos a cura, ao menos nesse aspecto, em tese, "todos estamos no mesmo barco", esta afirmação descontextualizada obscurece extraordinariamente a compreensão do problema. Tudo precisa ser contextualizado. O proverbial "fique em casa" pressupõe a superação de condições materiais brutais: ter alimentação minimamente suficiente, ter um lar
} 
todos nós habitantes do mesmo lar; somos habitantes deste mundo - pelo menos até que nossas ambições colonizadoras se concretizem.

Se por todos os cantos aparentemente triunfa a lógica do capitalismo, segundo Davis, são os ditos socialistas que "devem encontrar todas as ocasiões para lembrar aos outros a urgência de uma solidariedade internacional" (DAVIS, 2020, p. 12). Não obstante, pode-se perguntar: catástrofes dessa natureza têm realmente potencial de evocar uma solidariedade internacional? Além das mortes, que outros temores a pandemia revela?

\section{Necropolítica e pandemia}

É falso o dilema da escolha entre vidas e economia. Independente da escolha política neoliberal, a pandemia constrange todos, os porta-vozes do mercado, do sistema, e os críticos da lógica instrumental do capitalismo, a terem um olhar solícito ao cuidado com a vida. A economia reproduz um modelo bem específico de vida, a vida instrumental, a vida útil. Mas mesmo essa precisa ser preservada.

Se esta é de fato a lógica, o que justifica o descaso por parte de instituições financeiras para com a vida, desobedecendo ao que até o momento é a ferramenta mais eficiente no combate ao Covid-19, o isolamento social, então, mais que o falso dilema entre vida e economia, o que está em jogo é o potencial que o capitalismo tem de classificar vidas como supérfluas, a necropolítica, nas palavras de Mbembe (2018).

A necropolítica e o necropoder, segundo ele, é um espaço em que não há fronteiras entre vida e morte e "vastas populações são submetidas a condições de vida que lhes conferem o estatuto de 'mortosvivos" (MBEMBE, 2018, p. 71). Os sem-teto, os idosos, moradores de periferias com altos índices de violência e pouco investimento em saúde pública, a julgar pelo descaso que se impõe a eles, expostos a condições degradantes, podem ser classificados como vítimas do necropoder.

A necropolítica é exercida com os instrumentos de deixar viver e de fazer morrer. Tais instrumentos por sua vez, são produtos diretos do avanço do capitalismo. Krenak (2020, p. 8) afirma que quando o indivíduo para de produzir, passa a ser uma despesa. Ou você produz as condições para se manter vivo ou produz as condições para morrer.

Enquanto escrevemos este texto, o Brasil ultrapassa a China em número de mortos por Covid-19, e aguarda os efeitos catastróficos da insurgência do pico de contágio, que deve ocorrer nos próximos dias, ao mesmo tempo em que a China parece ter contido a pandemia, com o número de contágio inferior a mil.

Evidentemente, o fracasso ou o sucesso perante esta crise dependerá, em grande medida, das ações tomadas pelo poder público, pois "os vírus mudam o tempo todo. Mas as circunstâncias nas quais uma mutação se torna uma ameaça à vida dependem das ações humanas” (HARVEY, 2020, p. 15). A julgar pelas recentes declarações do presidente, minimizando os impactos da crise, e a ambição voraz do grande empresariado brasileiro, tempos sombrios se aproximam.

Krenak (2020, p. 5) foi preciso ao identificar o exercício da necropolítica em atuação no Brasil, ao afirmar que "o presidente da República disse outro dia que brasileiros mergulham no esgoto e não acontece

adequado ao isolamento. Não falamos apenas dos sem-teto, mas dos que se apinham em moradias minúsculas nas quais a casa é nela mesma um aglomerado. Segundo Maranhão (2020, p. 4), "até a teoricamente trivial fórmula ‘água e sabão' salva vidas precisa ser contextualizada. Sabe-se que muitas comunidades economicamente vulneráveis e vítimas de um racismo ambiental estruturado não têm água encanada nas torneiras de forma regular e segura. Sabão é um item de luxo". Condições ambientais, sociais, econômicas, etárias, de saúde influenciam no contágio e propagação do vírus. 
nada. O que vemos nesse homem é o exercício da necropolítica, uma decisão de morte”. A necropolítica funciona como uma espécie de darwinismo social. Santos (2020) visualiza que governos de extrema-direita ou de direita neoliberal têm operado nessa lógica. Por consequência, foram os que mais falharam no combate à pandemia.

[...] a eliminação de parte das populações que já não interessam à economia, nem como trabalhadores nem como consumidores, ou seja, populações descartáveis como se a economia pudesse prosperar sobre uma pilha de cadáveres ou de corpos desprovidos de qualquer rendimento. Os exemplos mais marcantes são a Inglaterra, os EUA, o Brasil, a Índia, as Filipinas e a Tailândia. (SANTOS, 2020, p. 26).

A necropolítica operando juntamente com uma dose de darwinismo social tem feito vítimas em várias parte do mundo e exposto cada vez mais o abismo de crise humanitária que estamos submersos. "Esse pacote chamado de humanidade vai sendo descolado de maneira absoluta desse organismo que é a Terra, vivendo numa abstração civilizatória que suprime a diversidade, nega a pluralidade das formas de vida, de existência e de hábitos.” (KRENAK, 2020, p. 6).

\section{Vigilância e isolamento social}

Se o contexto em que surge, no centro da segunda maior economia mundial, numa província que, não obstante, estabelece redes de relações que ligam Wuhan, onde surgiu a pandemia, às Ilhas Maldivas, Filipinas, Madagascar, ao planeta, em suma, e o mesmo ocorreria com qualquer parte do globo, é novo, outros eventos que desafiam a humanidade podem iluminar, ao menos em parte, o evento presente.

Como dissemos, os verdadeiros transes dessa época somente serão compreendidos quando a pandemia for seguramente um fenômeno superado. A metáfora da guerra contra o coronavírus, frequentemente utilizada, parece, no entanto, ilustrativa; a guerra é igualmente catastrófica, é um fenômeno excepcional e mobiliza esforços somente possíveis em situações de anormalidade. E, possivelmente, desde as duas grandes guerras, esse é o maior desafio que a humanidade enfrenta. Perguntar quais temores as grandes catástrofes históricas sinalizam pode, portanto, nos aproximar do problema.

Paralelamente ao exercício da necropolítica sob a falsa dicotomia "vidas ou economia" está o debate sobre as políticas de isolamento social. Alguns pensadores demonstraram preocupação com o aumento do aparato de vigilância do Estado sobre os cidadãos. Um dos primeiros a se manifestar sobre o tema foi o filósofo italiano Giorgio Agamben (2020).

As medidas tomadas tanto no âmbito econômico quanto no jurídico indicam a emergência de um estado de exceção, que Agamben define como "um vazio e uma interrupção do direito" (AGAMBEN, 2004, p. 75), não no sentido que o termo adquiriu no nazismo, um estado em que o direito foi completamente interrompido por 12 anos, mas porque o evento, em si mesmo excepcional, solicita condições jurídicas e econômicas diferenciadas.

Algumas delas são cruciais para o combate à pandemia. Em condições excepcionais, quando a "mão invisível do mercado" fraqueja, em crises econômicas, em guerras, ou sob alegação da necessidade de medidas de segurança nacional - não raramente utilizadas para sustentar tiranias, como aconteceu no golpe militar de 1964, em nosso país, ou a farsa da conspiração judaica, que Hitler utilizou para justificar a perseguição totalitária -, ou mesmo sob justificativas legítimas, como é o caso presente, em que os agentes políticos devem reivindicar protagonismo, é preciso estaratentos a medidas que ultrapassem as medidas de segurança e se aproximem das implantadas em tiranias. 
Não precisamos evocar aqui as medidas excepcionais tomadas em tiranias. Outro evento, muito próximo do nosso, parece mais paradigmático. A resposta dos Estados Unidos ao ataque às torres gêmeas, em 11 de setembro de 2001, soube-se recentemente, através de Edward Snowden, desencadeou como resposta um esquema de espionagem global até mesmo de países que não apresentavam ameaça alguma, diretamente, como o Brasil.

Uma vez que não dispomos de antídoto, até o momento, porém, a única medida eficaz é o isolamento social completo. A situação é de tal maneira atípica que o isolamento social é recomendado igualmente a todos, doentes e sãos. Há inclusive quem sugira, por meio dos sinais telefônicos, o monitoramento de toda a população, a fim de conter os avanços da pandemia. E é perfeitamente possível que esta tenha sido uma das principais ferramentas utilizadas pelo governo chinês para combatê-la.

Há que se considerar, no entanto, segundo Agamben (2004), o perigoso monopólio do enorme aparato de controle utilizado nestas situações excepcionais e criar ferramentas que impeçam governos democráticos de ampliar o estado de exceção e constituí-lo como regra².

Santos (2020), ao discordar de Agamben sobre a possibilidade da implementação de um permanente estado de exceção, aponta a excepcionalidade desta exceção, que nos obriga a submeter a todos, doentes e sãos, à quarentena.

Sendo a pandemia um evento próprio da modernidade, que se movimenta na tensão entre segurança e perigo, o que temos atualmente com o isolamento social é a intensificação de uma dimensão institucional da modernidade, que é a vigilância. Ela se caracteriza pela supervisão das atividades da população pelo monopólio político da força (GIDDENS, 1991, p. 69).

$\mathrm{Na}$ China, por exemplo, o Estado possui, através dos fornecedores da internet e de telefonia celular, acesso a determinados dados digitais dos cidadãos que sejam úteis no combate à pandemia. Não somente na China como em alguns países da Ásia, utiliza-se no enfrentamento ao coronavírus o que Han (2020) denomina de vigilância digital. Dessa forma, o aparato de vigilância torna-se cada vez mais sofisticado e, como toda invenção social, pode ser usado de diversas maneiras.

\section{Considerações finais}

O surto da pandemia de Covid-19 já é sentido em todas as partes do globo. Expôs concomitantemente as contradições do livre-mercado. O mercado, cuja ética é sinônimo de lucro, é incapaz de superar os contrastes sociais gritantes. É em momentos críticos como o nosso que o axioma "é a política que determina a economia, e não o inverso" deve ser proclamado em alta voz.

\footnotetext{
2 E aqui convém uma ressalva importante. Agamben tem sido alvo de duras críticas ao negar a necessidade de medidas de isolamento social, sob pretexto de que essas medidas poderiam ampliar os dispositivos de controle à disposição do Estado. Longe de nós endossarmos as críticas de Agamben ao isolamento social. Não obstante, ao nos colocarmos contra o posicionamento de Agamben, ao aplicar ingenuamente sua teoria do estado de exceção a um evento que é, nele mesmo, sui generis, - a título de exemplo, vale lembrar que as medidas de isolamento só demonstram eficácia quando nivelam todos, doentes e sãos, obrigando-os a ficarem em casa - não seguimos o percurso de seus críticos mais mordazes, que comprometem toda a filosofia do autor em função desse evidente equívoco. Sobre críticas dessa natureza, vale conferir o artigo de Yara Frateschi (2020), intitulado Agamben sendo Agamben: o filósofo e a invenção da pandemia, disponível em: http://blogdaboitempo.com.br/2020/05/12/agamben-sendo-agamben-ofilosofo-e-a-invencao-da-pandemia/ e acessado em 18/05/2020. Complementar a este artigo, é interessante consultar o artigo de Ruiz (2020) que, sendo fiel à filosofia de Agamben, não obstante não foge do bom-senso ao compreender a necessidade de medidas excepcionais, como o isolamento social, durante a pandemia. Conferir: 0 estado de exceção e a pandemia mascarada. Disponível em: http://www.ihu.unisinos.br/598874-o-estado-de-excecao-e-apandemia-mascarada-artigo-de-castor-bartolome-ruiz. Acessado em 18/05/2020.
} 
Se, como é consensual entre os pesquisadores, praticamente nenhum país do mundo tem uma infraestrutura de saúde capaz de acolher a imensidão numérica de pacientes infectados, o Brasil enfrenta contradições mais agudas. A crise reivindica da classe política protagonismo, uma vez que o mercado mostra-se incapaz de uma ética que não seja sinônimo de lucro, e, dentre as infinitas possibilidades de enfrentamento da pandemia, diante do crescente número de mortos, nem mesmo do porta-voz mais vociferante do livremercado esperaríamos o trivial "e daí?”, do presidente da república.

Como dissemos, é impossível uma análise do evento com a alegada imparcialidade de um historiador mais ou menos isento. Escrevemos o texto para, literalmente, enfrentarmos o tema. É terrível que o país encare uma crise na saúde pública, na economia, e ao mesmo tempo tenha que lidar com uma crise na política e uma gestão pouco razoável. É preciso resistir.

\section{Referências}

AGAMBEN, G. (2003) Estado de exceção: homo sacer, II, I. Tradução: Iraci D. Poleti. São Paulo: Boitempo, 2004.

BADIOU, A. (2020) Sobre a situação epidêmica. In: DAVIS, Mike, et al: Coronavírus e a luta de classes. Terra sem Amos: Brasil, 2020.

CHOMSKY, N. (2020) Chomsky: "coronavírus é algo sério o suficiente, mas há algo mais terrivel se aproximando". Abril de 2020. Acessado em 04/05/2020 e encontrado em: http://dialogosdosul.operamundi.uol.com.br/direitos-humanos/63998/chomsky-coronavirus-e-algo-serio-o-suficien te-mas-ha-algo-mais-terrivel-se-aproximando.

DAVIS, M. (2020) A crise do coronavírus é um monstro alimentado pelo capitalismo. In: DAVIS, M, et al:Coronavirus e a luta de classes. Terra sem Amos: Brasil, 2020.

ELIAS, N. (1992) Os alemães: a luta pelo poder e a evolução do habitus nos séculos XIX e XX. Tradução: Álvaro Cabral.Rio de Janeiro: Jorge Zahar, 1997.

FRATESCHI, Y. (2020) Agamben sendo Agamben: o filósofo e a invenção da pandemia. Maio de 2020. Acessado em 18/05/2020 e encontrado em: http://blogdaboitempo.com.br/2020/05/12/ agamben-sendo-agamben-o-filosofo-e-a-invencao-da-pandemia.

GIDDENS, A. (1991) As consequências da modernidade. Tradução: Raul Fiker.São Paulo: Unesp, 1991.

HAN, Byung-Chul. (2020) O coronavírus de hoje e o mundo de amanhã, segundo o filósofo ByungChulHan. Março de 2020.Acessado em 08/05/2020 e encontrado em: http://www.ihu.unisinos. br/78-noticias/597343-o-coronavirus-de-hoje-e-o-mundo-de-amanha-segundo-o-filosofo-byungchul-han.

HARVEY, D. (2020) Política anticapitalista em tempos de Covid-19. In: DAVIS, M., et al: Coronavírus e a luta de classes. Terra sem Amos: Brasil, 2020.

HEGEL, G.W.F. (1918) Prefácio. In: HEGEL, G.W.F. Princípios da filosofia do direito. São Paulo: Martins Fontes, 1997.

MBEMBE, A. (2017) Achille Mbembe: “A era do humanismo está terminando”. Janeiro de 2017. Acessado em 07/05/2020 e encontrado em:http://www.ihu.unisinos.br/186-noticias/noticias2017/564255-achille-mbembe-a-era-do-humanismo-esta-terminando.

- (2018). Necropolítica: biopoder, soberania, estado de exceção, política da morte. São 
Paulo: n-1 edições, 2018.

MARANHÃO, R. A. (2020) "Os cientistas sociais no combate ao coronavírus e contra a necropolítica: primeiras batalhas”. Boletim de conjuntura (BOCA): 5, 1-14.

MORIN, Edgar. (2020) "Vivemos em um mercado planetário que não soube suscitar fraternidade entre os povos". Entrevista com Edgar Morin". Abril de 2020. Acessado em 07/05/2020 e encontrado em: http://www.ihu.unisinos.br/598089-vivemos-em-um-mercado-planetario-que-nao-sou be-suscitar-fraternidade-entre-ospovos-entrevista-com-edgar-morin.

RUIZ, C. B. (2020) O estado de exceção e a pandemia mascarada. Maio de 2020. Acessado em 18/05/2020 e encontrado em: http://www.ihu.unisinos.br/598874-o-estado-de-excecao-e-a-pandemia-mascarada-artigo-de-castor-bartolome-ruiz.

SANTOS, B. de S. (2020) A cruel pedagogia do vírus. Coimbra: Almedina, 2020.

ŽlŽEK, S. (2020). Um golpe como o de "Kill Bill" no capitalismo. In: DAVIS, M, et al: Coronavírus e a luta de classes. Terra sem Amos: Brasil, 2020. p. 43-47.

Artigo recebido em: 18 de maio de 2020

Artigo aceito em: 28 de junho de 2020 